\title{
Analisis Kesesuaian Lahan Komoditas Unggulan Wilayah Pesisir Selatan Kabupaten Purworejo
}

\author{
Ismi Nuari Puspitaningrum, Sudrajat, Andri Kurniawan
}

\author{
Masuk: 18112020 / Diterima: 17012021 / Dipublikasi: 01122021
}

\begin{abstract}
The diversity of potentials in the southern coastal area of Purworejo Regency is one of the basic assets for economic development. However, the reality is that the diversity of potential superior commodities from the agricultural and non-agricultural sectors has not become the basis for the management of coastal areas, one of which is reflected in the coastal management policies that have been established and implemented in the southern coastal area of Purworejo Regency. Based on this, the research is focused on mapping various types of superior commodities as the basis for managing the southern coastal area of Purworejo Regency based on land suitability. In this study, the data used included primary data obtained through expert choice interviews and field observations, and secondary data obtained through institutional surveys. The data is processed by analytical methods in the form of $L Q$ analysis, Shift share, and land suitability map overlay. The results of the study concluded that there were various types of superior commodities in the agricultural sector in the form of field rice, lowland rice, maize, sweet potatoes, coconut, sugar cane, cashew nuts, goats, sheep, chickens, wild ducks, rabbits and pond fisheries. Some of the leading commodities do not have a suitable land suitability class, but by overcoming limiting factors, they have a great potential to be developed.
\end{abstract}

Key words: Superior Commodities; Land Suitability; LQ; Shift Share

\begin{abstract}
Abstrak Keberagaman potensi unggulan yang ada di kawasan pesisir selatan Kabupaten Purworejo merupakan salah satu modal dasar dalam pembangunan ekonomi. Namun kenyataannya keragaman potensi komoditas unggulan dari sektor pertanian dan non pertanian belum menjadi basis dalam pengelolaan wilayah pesisir, salah satunya tercermin dalam kebijakan pengelolaan pesisir yang telah ditetapkan dan dilaksanakan di wialyah pesisir selatan Kabupaten Purworejo. Berdasarkan hal tersebut maka penelitian difokuskan untuk memetakan berbagai jenis komoditas unggulan sebagai basis dalam pengelolaan wilayah pesisir selatan Kabupaten Purworejo berdasarkan kesesuaian lahan. Pada penelitian ini, data yang digunakan meliputi data primer yang diperoleh melalui wawancara expert choice serta observasi lapangan, dan data sekunder yang diperoleh melalui survei institusional. Data-data tersebut diolah dengan metode analisis berupa analisis LQ, Shift share, dan overlay peta kesesuaian lahan. Hasil penelitian menyimpulkan bahwa terdapat berbagai jenis komoditas unggulan sektor pertanian berupa padi ladang, padi sawah, jagung, ketela rambat, kelapa deres, tebu, jambu mete, kambing, domba, ayam, itik entog, kelinci serta perikanan tambak. Beberapa komoditas unggulan tidak memiliki kelas kesesuaian lahan yang sesuai, namun dengan mengatasi faktor pembatas, memiliki potensi yang besar untuk dikembangkan.
\end{abstract}

Kata kunci: Komoditas Unggulan; Kesesuaian Lahan; LQ; Shift Share

This is an open access article under the $\underline{C C B Y-S A}$ license.

Copyright @ 2021 by Author. Published by Universitas Pendidikan Ganesha.

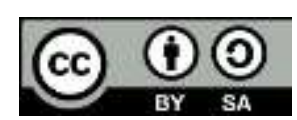

Ismi Nuari Puspitaningrum ${ }^{1}$, Sudrajat ${ }^{1}$, Andri Kurniawan ${ }^{1}$ 'Universitas Gadjah Mada, Indonesia

isminuari@mail.ugm.ac.id

\section{Pendahuluan}

Indonesia sebagai negara

kepulauan dengan panjang garis pantai 99.093 km (Poerwadi, 2018) memiliki wilayah kepesisiran yang luas serta 
karakteristik yang beragam dengan segala potensinya. Selain itu, Indonesia mempunyai jumlah penduduk kurang lebih 220

juta jiwa, dimana sekitar kurang lebih 60 persen penduduknya hidup serta bermukim di sekitar wilayah pesisir dan sebagian besar diantaranya menggantungkan kepada keberadaan sumberdaya alam pesisir dan lautan. Hal tersebut berpeluang besar untuk dijadikan sumber pertumbuhan ekonomi baru dan pembangunan berupa aneka sumberdaya alam dan jasa-jasa lingkungan yang belum dimanfaatkan secara optimal (Resosudarmo et.al.,2000). Sayangnya potensi yang ada tersebut belum banyak meningkatkan kesejahteraan masyarakat yang disebabkan kurang optimalnya pemanfaatan potensi sumber daya yang ada menjadi sebuah komoditas unggulan.

Pengembangan wilayah pesisir selatan Jawa, selain akan mampu menciptakan peluang pertumbuhan ekonomi baru yang bertumpu pada hasil produksi perikanan, namun diharapkan juga mampu merangsang pertumbuhan ekonomi lainnya di bidang pariwisata, industri maupun jasa (Resosudarmo et.al., 2000; Suprapto et al., 2016). Namun pada kenyataanya, pengembangan sumberdaya alam yang masih bertumpu pada sektor perikanan belum sepenuhnya mampu menciptakan wilayah pesisir dengan tingkat kesejahteraan penduduknya yang lebih tinggi. Menurut Alecsandru dan Raluca, (2015); Permana dan Asmara, (2010) dalam hasil penelitian, penyebab lambannya perkembangan ekonomi di wilayah pesisir selatan Jawa disebabkan karena akses yang belum sempurna maupun belum optimalnya pemanfaatan semua potensi sumberdaya yang merupakan komoditi unggulannya.

Sumberdaya alam di wilayah pesisir yang meliputi komoditas di bidang pertanian dan bidang non pertanian, belum terpetakan mana yang termasuk komoditas unggulan dan mana yang tidak. Analisa dan pemetaan potensi komoditas unggulan sangat diperlukan, untuk mengetahui potensi unggulan di bidang tersebut sehingga dapat diprediksi persebaran lahan dan hasil panen di masingmasing wilayah dan sebagai rekomendasi pemanfaatan lahan yang sesuai dengan persyaratan kualitas dan karakteristik lahan (Ahaliki, 2016) (Djaenudin, et.al, 2011). Evaluasi kesesuaian lahan merupakan suatu upaya dalam pemanfataan atau penilaian terhadap sumberdaya lahan berdasarkan potensi yang dimiliki lahan tersebut (Suratman dkk, 1993). Penilaian dilakukan untuk mendapatkan penyusunan kebijakan, pemanfaatan lahan dan pengelolaannya agar dapat bermanfaat serta sesuai dengan fungsi lahan tersebut

Lokasi penelitian berada di pesisir selatan Kabupaten Purworejo, Jawa Tengah unit analisis pada penelitian ini adalah berdasar wilayah administrasi tingkat kecamatan. Hal tersebut juga sesuai dengan UU No 27 Tahun 2007 dimana disebutkan (bagian penjelasan) bahwa batas wilayah pesisir ke arah darat mencakup wilayah administrasi kecamatan. Secara administrasi wilayah pesisir selatan 
Kabupaten Purworejo berada di 3 (tiga) wilayah kecamatan yaitu Kecamatan Grabag, Kecamatan Ngombol dan Kecamatan Purwodadi. Secara umum wilayah pesisir selatan Kabupaten Purworejo yang merupakan kawasan pertanian lahan sawah dan lahan pesisir banyak menghasilkan komoditas pertanian dan non pertanian, namun pada kenyataannya komoditas-komoditas tersebut belum dianalisis sebagai komoditas unggulan yang akan menjadi pusat produksi dan agen pendistribusi. Berpijak dari permasalahan tersebut maka penelitian ini menganalisis jenis komoditas unggulan yang ada di wilayah pesisir selatan Kabupaten Purworejo dan mengevaluasi kelas kesesuaian lahan komoditas unggulan.

\section{Metode}

\section{Pengumpulan Data}

Lokasi penelitian ini berada di wilayah pantai selatan Kabupaten Purworejo, Jawa Tengah. Menurut Kawik (2003), Setiawan (2004) dan Djunaedi (2002), untuk menentukan batas-batas ruang fisik pesisir pada suatu wilayah di berbagai negara dan di Indonesia sering dilakukan dengan cara mengkompromikan keseragaman fisik, sosial, ekonomi dan budaya masyarakat serta saling ketergantungan dan keterkaitan dengan daerah lain yang jauh dari pantai. Berdasarkan hal tersebut maka pendekatan batas wilayah pantai selatan di Kabupaten Purworejo dalam penelitian ii menggunakan pendekatan wilayah administrasi. Secara administratif wilayah pesisir selatan Kabupaten Purworejo berada pada 3 (tiga) wilayah kecamatan, yaitu
Kecamatan Grabag, Kecamatan Ngombol dan Kecamatan Purwodadi.

Adapun dasar pertimbangan pendekatan kecamatan adalah (1) terkait dengan keterlibatan warga dalam berbagai kegiatan ekonomi baik langsung maupun tidak langsung di wilayah pesisir seperti; dalam kegiatan perikanan atau tambak laut, pariwisata serta pertanian dan kegiatan lainnya dan (2) di tingkat kecamatan data yang tersedia lebih banyak berkaitan dengan topik penelitian lengkap ini.

Penelitian ini menggunakan dua jenis data yaitu data primer dan sekunder. Data primer diperoleh dengan melakukan observasi lapangan untuk mengetahui penggunaan lahan existing, sedangkan untuk data sekunder diperoleh dengan melakukan survey institusional ke dinas terkait seperti Dinas Pertanian, Peternakan dan Kelautan Kabupaten Purworejo dan Dinas Pekerjaan Umum dan Perumahan Rakyat Kabupaten Purworejo.

\section{Teknik Analisis Data}

Pemetaan Komoditas Unggulan

Penentuan komoditas unggulan di Kabupaten Purworejo didapatkan dengan cara mengetahui luas panen komoditas yang selanjutnya dianalisis dengan menggunakan metode Location Quotient (LQ) (Harinta et al., 2018). Secara matematis, formulasi $L Q$ dalam penelitian ini adalah :

$$
L Q i j=\frac{X i j / X i}{X j / X}
$$

Dimana:

$\mathrm{Xij}=$ produksi panen komoditas $k e-j \mathrm{di}$ kecamatan ke-i 
Xi. = total produksi panen komoditas di kecamatan ke-i

$X . j=$ total produksi panen komoditas ke-j di semua wilayah

$\mathrm{X}=$ total produksi panen semua komoditas di semua wilayah

LQ diinterpretasi dengan menggunakan kriteria (Ron hood, 1988 dalam Sari 2010) sebagai berikut:

LQ > 1 menunjukkan terdapat konsentrasi relatif disuatu wilayah dibandingkan dengan keseluruhan wilayah. Hal ini berarti komoditas i disuatu wilayah merupakan sektor basis yang berarti komoditas i di wilayah itu memiliki keunggulam komparatif.

$\mathbf{L Q}=\mathbf{1}$, merupakan sektor non basis, artinya komoditas i disuatu wilayah tidak memiliki keunggulan komparatif, produksi komoditas yang dihasilkan hanya cukup untuk memenuhi kebutuhan sendiri dalam wilayah itu.

$\mathbf{L Q}<\mathbf{1}$, merupakan sektor non basis, artinya komoditas i disuatu wilayah tidak memiliki keunggulan komparatif, produksi komoditas i di wilayah itu tidak dapat memenuhi kebutuhan sendiri dan harus mendapat pasokan dari luar wilayah.

Persamaan indeks spesialisasi yang digunakan adalah metode Shift Share. Analisis shift-share yang digunakan untuk menganalisis dan mengetahui pergeseran dan peranan perekonomian di daerah.

$$
\text { St }=\text { Vjt }-(\mathrm{Vt} / \mathrm{Va}) \cdot \mathrm{Vja}
$$

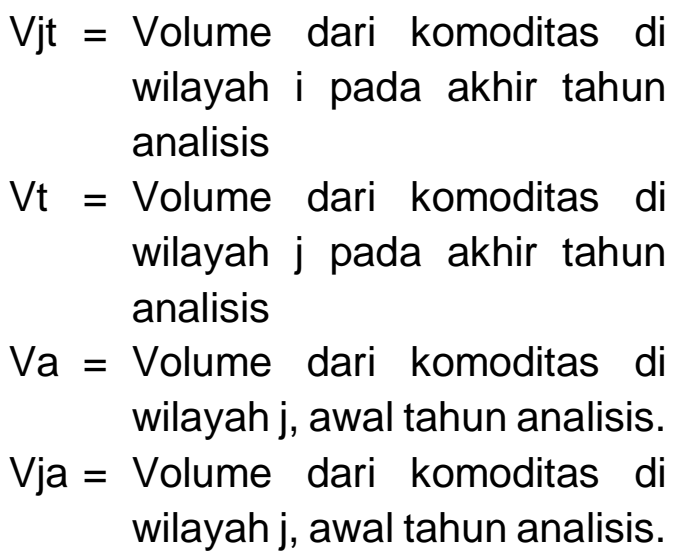

Shift Share diinterpretasikan dengan kriteria sebagai berikut.

1) Nilai Shift Share $>1=D S$ positif (+) menunjukkan bahwa pertumbuhan sektor pada tingkat wilayah lokal lebih cepat dibandingkan dengan pertumbuhan sektor pada wilayah daerah.

2) Nilai Shift Share $<1=D S$ negatif (-) menunjukkan bahwa pertumbuhan sektor pada tingkat wilayah lokal lebih lambat dibandingkan dengan pertumbuhan sektor pada wilayah daerah

\section{Analisis Kesesuaian Lahan}

Pada penelitian ini evaluasi kesesuaian lahan dilakukan secara spasial menggunakan software ArcGIS, yaitu dengan cara overlay satuan peta tanah, erosi, suhu, curah hujan dan kelas lereng kemudian dikelaskan sesuai kriteria kesesuaian lahan (Tabel 1, Tabel 2, dan Tabel 3).

Dimana: 
Tabel 1. Matriks Kesesuaian Lahan Pertanian

\begin{tabular}{|c|c|c|c|c|}
\hline No & Kriteria & $\begin{array}{l}\text { Sesuai } \\
\text { (S1) }\end{array}$ & $\begin{array}{l}\text { Agak Sesuai } \\
\text { (S2) }\end{array}$ & $\begin{array}{l}\text { Tidak Sesuai } \\
\text { (N) }\end{array}$ \\
\hline \multirow[t]{3}{*}{1.} & $\begin{array}{l}\text { Kemiringan } \\
\text { Lereng (\%) }\end{array}$ & & & \\
\hline & - Sawah & $0-3$ & $3-5$ & $>5$ \\
\hline & - $\quad$ Tegalan & $0-5$ & $5-8$ & $>8$ \\
\hline 2. & $\begin{array}{l}\text { Materi penyusun } \\
\text { utama (tekstur } \\
\text { tanah) }\end{array}$ & $\begin{array}{l}\text { Geluh (lekat) lempung } \\
\text { berpasir, geluh berdebu, } \\
\text { geluh berlempung }\end{array}$ & $\begin{array}{c}\text { Geluh lempung } \\
\text { berdebu, lempung }\end{array}$ & Kerikil \\
\hline 3. & Proses Genesa & Fluvial & $\begin{array}{c}\text { Fluvio - marin, Aeolio - } \\
\text { marin, solusional, } \\
\text { volkanik, struktural }\end{array}$ & Marin \\
\hline \multirow[t]{3}{*}{4.} & Iklim & & & \\
\hline & $\begin{array}{ll}- & \mathrm{CH} \text { tahunan } \\
& \text { rata-rata }(\mathrm{mm})\end{array}$ & $1500-3000$ & $1000-1500$ & $\begin{array}{l}<1000 \\
>3000\end{array}$ \\
\hline & $\begin{array}{l}\text { Suhu rata-rata } \\
\text { tahunan }\left({ }^{\circ} \mathrm{C}\right)\end{array}$ & $25-30$ & $30-32 ;<24$ & $>32 ;<18$ \\
\hline
\end{tabular}

Sumber: Wahyunto et al. (2016)

Tabel 2. Matriks Kesesuaian Lahan Perikanan (Tambak)

\begin{tabular}{|c|c|c|c|c|}
\hline No & Kriteria & $\begin{array}{l}\text { Sesuai } \\
\text { (S1) }\end{array}$ & $\begin{array}{l}\text { Agak Sesuai } \\
\text { (S2) }\end{array}$ & $\begin{array}{l}\text { Tidak Sesuai } \\
(\mathrm{N})\end{array}$ \\
\hline 1. & Kemiringan Lereng (\%) & $<0,1$ & $0,1-1$ & $>2$ \\
\hline 2. & $\begin{array}{l}\text { Materi penyusun utama } \\
\text { (tekstur tanah) }\end{array}$ & $\begin{array}{l}\text { Lempung, } \\
\text { lempung } \\
\text { berpasir }\end{array}$ & $\begin{array}{l}\text { Geluh (lekat), geluh } \\
\text { berlempung, geluh } \\
\text { berpasir, geluh } \\
\text { lempung berdebu }\end{array}$ & Pasir \\
\hline 3. & Proses Genesa & Fluvio-marin & Marin & $\begin{array}{c}\text { Solusional, } \\
\text { structural, volkanik }\end{array}$ \\
\hline 4. & Kisaran pasang surut (m) & $1,5-2,5$ & $1,0-1,5 ; 2,5-3$ & $<0,5 ;>3,5$ \\
\hline \multirow[t]{4}{*}{5.} & Kondisi Air (Hidrologi) & & & \\
\hline & - $\quad$ Salinitas (ppt) & $15-25$ & $10-15 ; 25-32$ & $<5 ;>40$ \\
\hline & $-\quad$ Suhu $\left({ }^{\circ} \mathrm{C}\right)$ & $28-30$ & $26-28 ; 30-35$ & $<12 ;>40$ \\
\hline & $-\mathrm{pH}$ & $7,5-8,5$ & $6,9-7,5 ; 8,5-9,5$ & $>4,0 ;<11,0$ \\
\hline 6. & $\begin{array}{l}\text { Iklim CH tahunan rata-rata } \\
(\mathrm{mm})\end{array}$ & $2500-3000$ & $1000-2000$ & $<1000 ;>3500$ \\
\hline
\end{tabular}

Sumber: Mustafa (2012)

Tabel 3. Matriks Kesesuaian Lahan Peternakan Ruminansia Kecil

\begin{tabular}{|c|c|c|c|c|}
\hline No & Kriteria & $\begin{array}{l}\text { Sesuai } \\
\text { (S1) }\end{array}$ & $\begin{array}{l}\text { Agak Sesuai } \\
\text { (S2) }\end{array}$ & $\begin{array}{l}\text { Tidak Sesuai } \\
\text { (N) }\end{array}$ \\
\hline 1. & $\begin{array}{l}\text { Kemiringan Lereng } \\
(\%)\end{array}$ & $<0-8$ & $>8-15$ & $>40$ \\
\hline 2. & $\begin{array}{lr}\text { Materi } & \text { penyusun } \\
\text { utama } & \text { (tekstur } \\
\text { tanah) } & \end{array}$ & $\begin{array}{l}\text { Alluvial, Latosol, } \\
\text { Mediteran, } \\
\text { Regasol }\end{array}$ & $\begin{array}{c}\text { Podsolik Merah } \\
\text { Kuning, Grumusol, } \\
\text { Renzina }\end{array}$ & $\begin{array}{l}\text { Podsol, Litosol, Planosol, } \\
\text { Gleihumus, Organosol }\end{array}$ \\
\hline 3. & $\begin{array}{l}\text { Agroklimat (bulan } \\
\text { kering) }\end{array}$ & $<2$ bulan / tahun & 2-5 bulan / tahun & $>5$ bulan/tahun \\
\hline 4. & Ketinggian (m) & $0-100 \mathrm{~m}$ & $>100-500 \mathrm{~m}$ & $>1000 \mathrm{~m}$ \\
\hline
\end{tabular}

Sumber: Rusmana, et al (2006) 


\section{Hasil dan Pembahasan Jenis Komoditas Unggulan Pesisir Selatan Purworejo}

Secara umum pada wilayah pesisir selatan Purworejo yang meliputi kecamatan Grabag, Ngombol dan Purwodadi terdapat 28 jenis komoditas yang diusahakan terdiri dari komoditas pertanian dan komoditas non pertanian. Komoditas pertanian meliputi komoditas pada sektor pertanian, peternakan dan perikanan. Beragamnya komoditas yang ada diupayakan agar dapat bersaing dengan wilayah lain, salah satu upaya adalah dengan menentukan komoditas unggulan. Hasil analisis LQ (Tabel 4, Tabel 5 dan Tabel 6) menunjukkan bahwa setiap kecamatan memiliki komoditas di bidang pertanian, peternakan dan perikanan yang unggul secara komparatif minimal satu jenis yang ditandai dengan nilai $L Q>1$. Nilai $L Q>1$ menandakan bahwa komoditas tersebut merupakan komoditas unggul secara komparatif dan dapat memenuhi kebutuhan hingga ke wilayah luar kecamatan.

Komoditas yang memiliki keunggulan komparatif menjadi dasar bagi pengembangan ekonomi yang diharapkan dapat diekspor keluar daerah sehingga pendapatan yang diperoleh dapat dipergunakan untuk pembangunan dan meningkatkan sektor non basis.

Tabel 4. Nilai LQ Pada Komoditas Pertanian

\begin{tabular}{lccc}
\hline Komoditas & Kec. Ngombol & Kec. Grabag & Kec Purwodadi \\
\hline Padi Sawah & 1,26 & 0,75 & 1,15 \\
\hline Padi Ladang & 0 & 7,14 & 0,22 \\
\hline Jagung & 0,89 & 3,05 & 0,93 \\
\hline Ketela Pohon & 0,02 & 0,26 & 0,33 \\
\hline Ketela Rambat & 0,81 & 5,34 & 0 \\
\hline Kacang Tanah & 0,10 & 0,59 & 0,40 \\
\hline Kedelai & 0,02 & 0 & 0,02 \\
\hline Kacang Hijau & 0,44 & 0,06 & 0,34 \\
\hline Kelapa & 0,84 & 0,10 & 0,89 \\
\hline Kelapa Deres & 0,04 & 4,95 & 0,63 \\
\hline Tebu & 0 & 1,58 & 3,59 \\
\hline Jambu Mete & 8,09 & 0 & 0 \\
\hline Kakao & 0,35 & 0 & 0 \\
\hline
\end{tabular}

Tabel 5 Nilai LQ Pada Komoditas Peternakan

\begin{tabular}{lccc}
\hline Komoditas & Kec Ngombol & Kec. Grabag & Kec. Purwodadi \\
\hline Sapi & 1,0 & 2,4 & 1,2 \\
\hline Kambing PE & 0,1 & 0,2 & 0,0 \\
\hline Kambing Jawa & 0,3 & 0,4 & 0,3 \\
\hline Domba & 0,7 & 0,6 & 1,2 \\
\hline Ayam & 0,8 & 0,6 & 1,1 \\
\hline Itik & 2,1 & 3,1 & 1,5 \\
\hline Entog & 2,0 & 0,7 & 1,0 \\
\hline Kelinci & 0,6 & 4,8 & 0,7 \\
\hline
\end{tabular}

Tabel 6. Nilai LQ Pada Komoditas Perikanan

\begin{tabular}{lccc}
\hline Komoditas & Kec Ngombol & Kec. Grabag & Kec. Purwodadi \\
\hline Tawes & 0,1 & 0 & 0,1 \\
\hline Gurami & 0,1 & 0,2 & 0,1 \\
\hline
\end{tabular}


Analisis Kesesuaian Lahan Komoditas Unggulan Wilayah Pesisir Selatan Kabupaten Purworejo/Ismi Nuari Puspitaningrum, Sudrajat, Andri Kurniawan

\begin{tabular}{lccc}
\hline Nila/Mujahir & 0,1 & 0,1 & 0,2 \\
\hline Lele & 0 & 0,2 & 0,3 \\
\hline Bawal & 0,1 & 0,1 & 0,2 \\
\hline Tambak Udang Vanamei & 1,3 & 1,3 & 1,2 \\
\hline Tambak Nila/Mujahir & 1,3 & 1,3 & 1,2 \\
\hline
\end{tabular}

Kemudian untuk mengetahui dan menganalisis pergeseran dan peranan ekonomi daerah, maka digunakan analisis shift share. Komponen pertumbuhan pangsa wilayah yang positif, berarti bahwa sektor perekonomian tersebut lebih tinggi daya saingnya ketimbang sektor perekonomian yang sama pada tingkat yang lebih tinggi (wilayah acuan/wilayah himpunanya). Dalam penelitian ini menggunakan data tahun 2015-2019 untuk menganalisis pergeseran ekonomi daerah berdasarkan luas panen dan luas produksi komoditas. Berdasarkan hasil analisis shift share (Tabel 7).

Tabel 7. Hasil Analisis Shift Share Semua Komoditas Tahun 2015-2019

\begin{tabular}{|c|c|c|c|}
\hline Komoditas & Kec. Ngombol & Kec. Grabag & Kec Purwodadi \\
\hline Padi Sawah & 2956,4 & 347,7 & $-31891,3$ \\
\hline Padi Ladang & $\mathrm{N} / \mathrm{A}$ & 619,1 & $-26,5$ \\
\hline Jagung & $-138,1$ & $-1566,9$ & 783,4 \\
\hline Ketela Pohon & 36,0 & $-432,8$ & 1225,2 \\
\hline Ketela Rambat & 26,7 & 206,9 & $\mathrm{~N} / \mathrm{A}$ \\
\hline Kacang Tanah & 13,6 & $-273,4$ & $-31,5$ \\
\hline Kedelai & 59,0 & 276,7 & 57,4 \\
\hline Kacang Hijau & 0,0 & $-450,5$ & 59,3 \\
\hline Kelapa & 50,6 & $-3035,6$ & 752,3 \\
\hline Kelapa Deres & 0,0 & 9920,0 & $-449,1$ \\
\hline Tebu & $\mathrm{N} / \mathrm{A}$ & 23,2 & 165,2 \\
\hline Jambu Mete & 3,0 & $\mathrm{~N} / \mathrm{A}$ & $\mathrm{N} / \mathrm{A}$ \\
\hline Kakao & $-10,6$ & $\mathrm{~N} / \mathrm{A}$ & $\mathrm{N} / \mathrm{A}$ \\
\hline Sapi & $-307,8$ & $-12759,9$ & $-609,4$ \\
\hline Kambing PE & $-40,0$ & $-57,2$ & $-356,3$ \\
\hline Kambing Jawa & $-1534,5$ & 1493,2 & $-1984,9$ \\
\hline Domba & 1604,9 & $-598,9$ & 641,2 \\
\hline Ayam Buras & 7447,2 & 9669,8 & 12320,2 \\
\hline Itik & 8782,0 & 14122,4 & $-4435,0$ \\
\hline Entog & 8274,2 & 1288,7 & $-5308,5$ \\
\hline Kelinci & $\mathrm{N} / \mathrm{A}$ & 2223,7 & $\mathrm{~N} / \mathrm{A}$ \\
\hline Tawes & $-0,3$ & 0,1 & 14,6 \\
\hline Gurami & 0,0 & 0,6 & $-83,8$ \\
\hline Nila/Mujahir & $-45584,8$ & $-68443,2$ & $-53114,6$ \\
\hline Lele & $-30000,1$ & $-0,4$ & $-1138,0$ \\
\hline Bawal & 0,7 & 0,5 & $-12,1$ \\
\hline Tambak Udang Vanamei & 756098,3 & 1344580,3 & $-2747862,1$ \\
\hline Tambak Nila/Mujahir & 1494,8 & 8848,4 & $-15241,3$ \\
\hline
\end{tabular}


\begin{tabular}{rr}
\multicolumn{2}{r}{ Selanjutnya untuk mengetahui } \\
pengelompokan & komoditas \\
berdasarkan keunggulan & komparatif
\end{tabular} (Tabel 4, Tabel 5 dan Tabel 6) dan kompetitifnya (Tabel 7) dilakukan kombinasi hasil analisis LQ dan Shift Share dalam bentuk matrik kombinasi untuk memudahkan pengelompokkan komoditas.

\begin{tabular}{c|c} 
Kuadran III & $\begin{array}{c}\text { Kuadran I } \\
\text { Nilai } L Q<1 \text { dan } D S \\
>0\end{array}$ \\
& $>0$ \\
\hline Nilai $L Q>1$ dan $D S$ \\
Nilai $L Q>1$ dan $D S$ & Kuadran II \\
$<0$ & Nilai $L Q>1$ dan $D S$ \\
& $<0$
\end{tabular}

Berdasarkan matrik kombinasi tersebut, komoditas yang masuk dalam kuadran I adalah padi sawah, padi ladang, jagung, ketela rambat, kelapa deres, tebu, jambu mete, domba, ayam, itik, entog, kelinci, tambak udang vanamei dan tambak nila/mujahir. Komoditas-komoditas tersebut merupakan komoditas yang direkomendasikan menjadi komoditas unggulan karena unggul secara komparatif dan kompetitif.

\section{Komoditas Unggulan Berdasarkan Kesesuaian Lahan}

Analisis kesesuaian diarahkan pada komoditas unggulan terpilih. Masing-masing komoditas unggulan yang terpilih baik dari komoditas pertanian, peternakan dan perikanan, dalam pengembangannya sangat bergantung kepada keberadaan lahan yang sesuai. Hal tersebut sangat penting diketahui karena penggunaan lahan yang tidak sesuai peruntukannya tidak saja akan mengakibatkan menurunnya produktivitas tetapi juga dapat menyebabkan terjadinya degradasi lingkungan.

Selain itu dengan diketahuinya sebaran lahan, baik yang potensial maupun yang bermasalah berikut kendala dan kebutuhan input-nya, pengembangan sektor pertanian akan lebih terarah dan efisien (Djaenudin 2008).

Berdasarkan pencocokkan karakter lahan wilayah pesisir Purworejo dan syarat tumbuh komoditas unggulan pertanian, secara aktual komoditas padi sawah dan padi ladang memiliki kelas kesesuaian lahan S2, S3, dan N untuk padi sawah (Gambar 2), sedangkan untuk padi ladang (Gambar 3) adalah S1 dan S3. Faktor pembatas pada keduanya adalah tekstur tanah dan tingkat drainase

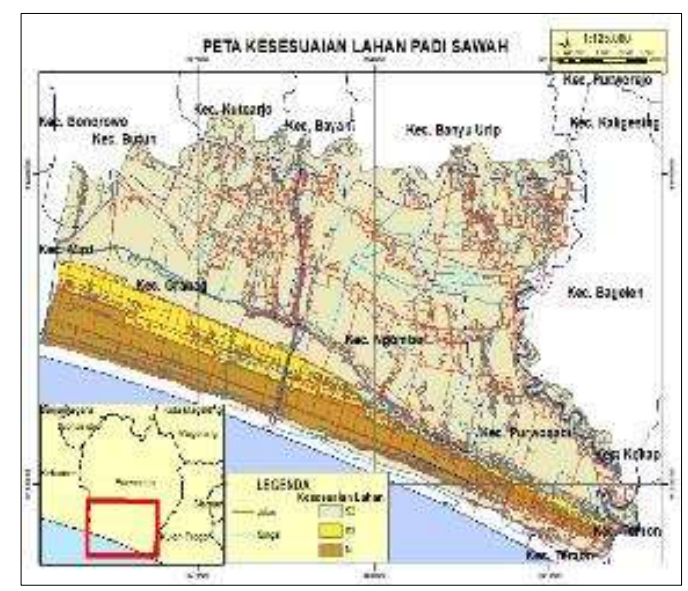

Gambar 2. Peta Kesesuaian Lahan Padi Sawah 


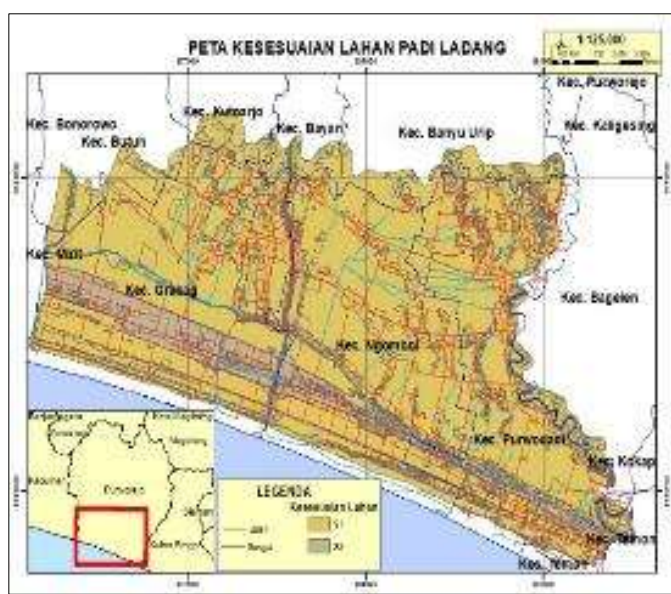

Gambar 3. Peta Kesesuaian Lahan Padi Ladang

Pencocokkan karakteristik lahan wilayah pesisir dan syarat tumbuh komoditas jagung dan juga ketela rambat memeperlihatkan bahwa secara aktual memiliki kelas S2, S3 dan $\mathrm{N}$ untuk komoditas jagung (Gambar 4). Sedangkan komoditas ketela rambat (Gambar 5) memiliki kelas kesesuaian lahan S3 dan N. Faktor pembatas yang berpengaruh pada pertumbuhan keduanya adalah tekstur tanah dan drainase yang cenderung terhambat sehingga tingkat konduktivitas hidrolik rendah dan daya menahan air juga rendah. Pada komoditas unggulan perkebunan, kelapa, tebu dan jambu memiliki masing-masing kelas kesesuaian lahan yang berbeda. Kelapa dan jambu merupakan tanaman yang sering dijumpai di pesisir selatan Purworejo, akan tetapi pada kelapa kelas kesesuaian lahan menunjukkan kelas S3 dan N (Gambar 6). Begitupun juga dengan tanaman jambu, yang menjadi komoditas unggulan di wilayah pesisir Purworejo. Jambu memiliki kelas kesesuaian lahan S2, S3, dan $\mathrm{N}$ (Gambar 7). Seperti komoditas kelapa, komoditas tebu juga memiliki kelas kesesuaian lahan S3 dan N (Gambar 8). Tekstur tanah dan drainase merupakan faktor pembatas yang paling dominan dalam pertumbuhan ketiga komoditas tersebut.
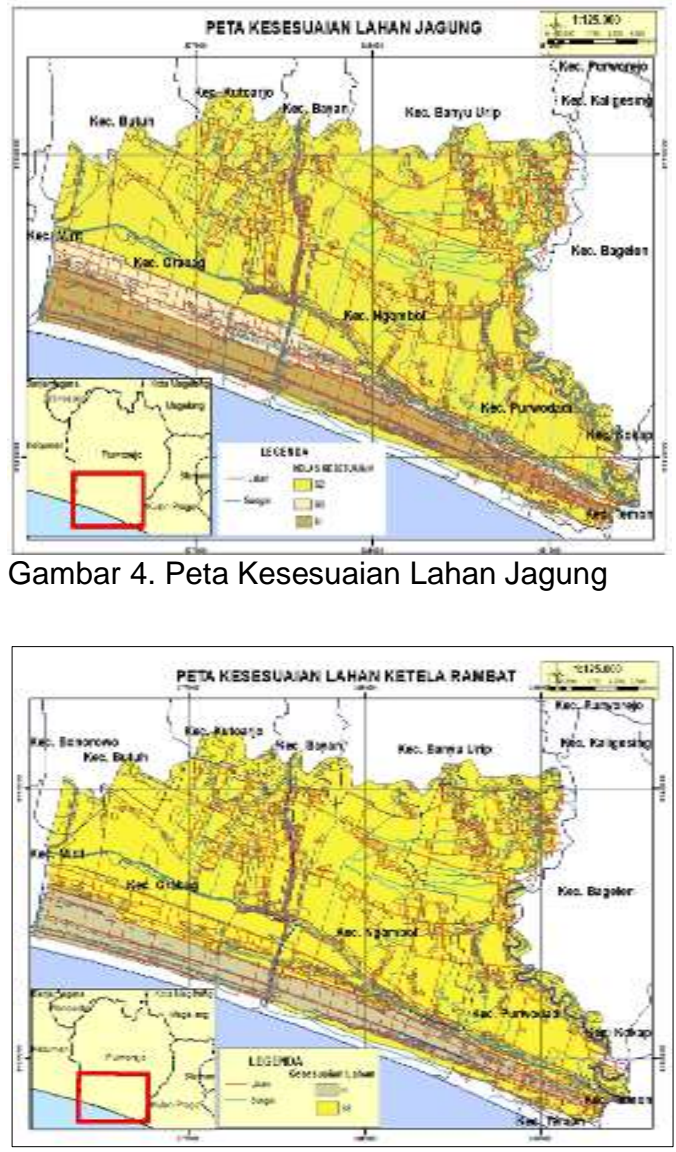

Gambar 5. Peta Kesesuaian Lahan Ketela Rambat

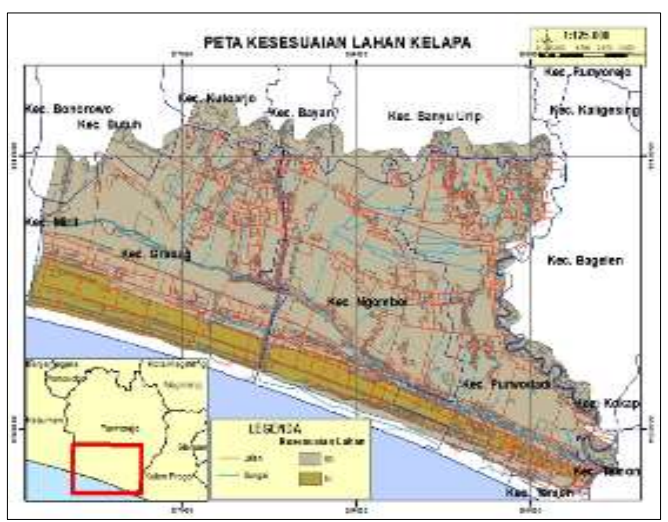

Gambar 6. Peta Kesesuaian Lahan Kelapa 


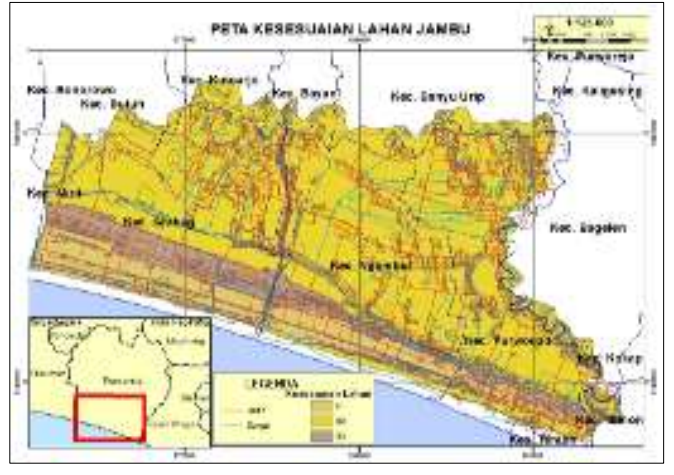

Gambar 7. Peta Kesesuaian Lahan Jambu

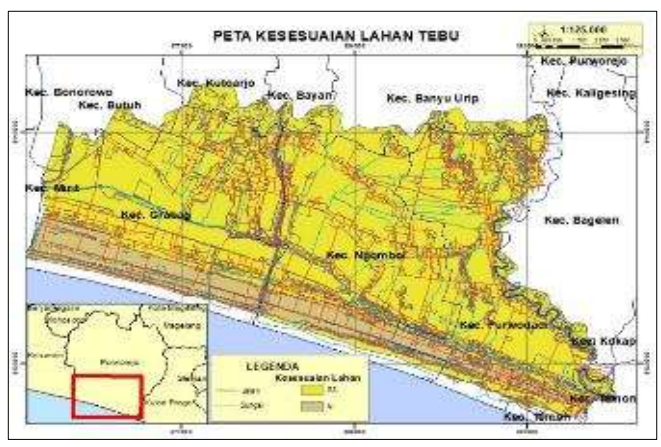

Gambar 8. Peta Kesesuaian Lahan Tebu

Pada komoditas peternakan, kesesuaian lahan juga dibutuhkan untuk menghasilkan hasil yang diharapkan. Kesesuaian lahan untuk ternak terutama ruminansia (dalam penelitian ini adalah domba) diperlukan dalam upaya meningkatkan produktivitas baik skala besar, industri peternakan ataupun peternakan rakyat. Semakin tinggi kesuburan tanah semakin besar pula peluang ternak untuk berkembang.

Berdasarkan pencocokkan karakteristik lahan wilayah pesisir, secara aktual peternakan ruminansia memiliki kelas keseuaian lahan S2 dengan tekstur tanah sebagai faktor pembatas (Gambar 9). Sedangkan pada komoditas unggulan peternakan yang berupa ternak tidak dievaluasi kesesuaian lahannya.

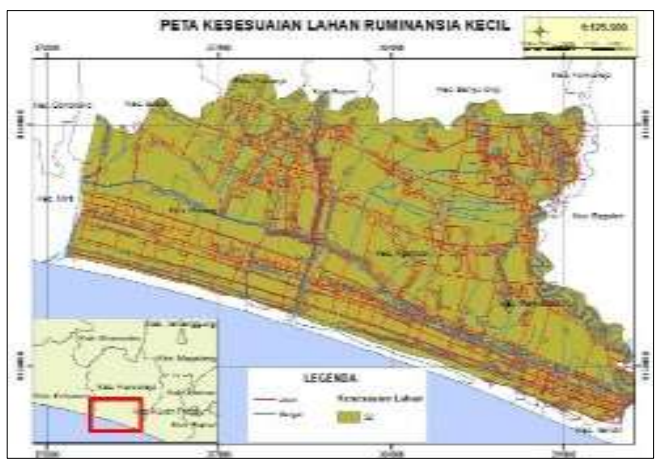

Gambar 9. Peta Kesesuaian Lahan Ruminansia

Komoditas

perikanan merupakan komoditas yang melekat pada wilayah pesisir. Hasil dari analisis komoditas unggulan, pada seluruh kecamatan di wilayah pesisi Purworejo memiliki komoditas unggulan yang sama yaitu tambak udang vanamei dan tambak nila/mujahir. Berdasarkan pencocokkan karakteristik lahan wilayah pesisir Purworejo, secara aktual perikanan tambak memiliki kelas kesesuaian lahan $\mathrm{N}$ dan S3 (Gambar 10). Tekstur tanah merupakan faktor pembatas yang paling berpengaruh dalam kesesuaian lahan pada perikanan tambak.

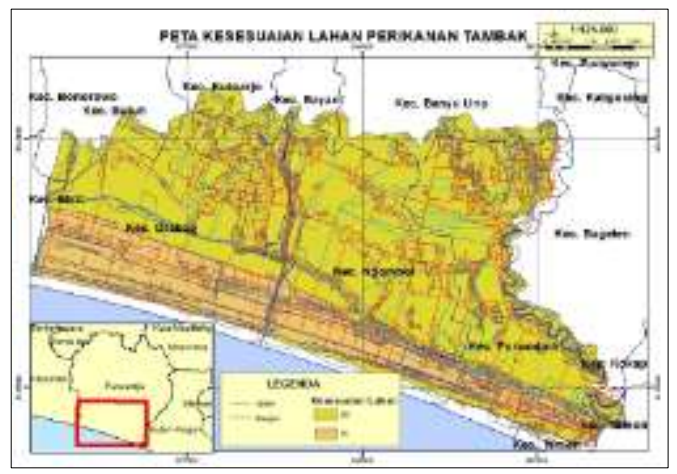

Gambar 10. Peta Kesesuaian Lahan Perikanan Tambak 
Tabel 8. Integrasi Komoditas Unggulan dengan Tingkat Kesesuaian Lahan

\begin{tabular}{clcccc}
\hline \multirow{2}{*}{ Bidang } & Komoditas Unggulan & \multicolumn{3}{c}{ Tingkat Kesesuaian Lahan (\%) } \\
& Padi Sawah & S1 & S2 & S3 & N \\
\hline \multirow{5}{*}{ Pertanian } & 0 & 79 & 8 & 13 \\
& Padi Ladang & 92 & 0 & 8 & 0 \\
& Jagung & 0 & 79 & 8 & 13 \\
& Ketela Rambat & 0 & 0 & 87 & 13 \\
& Kelapa Deres & 0 & 0 & 87 & 13 \\
& Tebu & 0 & 0 & 87 & 13 \\
& Jambu Mete & 0 & 79 & 8 & 13 \\
Peternakan & Domba (Ruminansia Kecil) & 0 & 100 & 0 & 0 \\
Perikanan & Tambak Udang Vanamei & 0 & 0 & 79 & 21 \\
\hline
\end{tabular}

Secara sederhana, integrasi antara komoditas unggulan dengan kesesuaian lahan tersaji pada Tabel 8. Berdasarkan hasil analisis kesesuaian lahan, dapat diketahui bahwa potensi wilayah pengembangan komoditas unggulan di wilayah pesisir Purworejo masih cukup besar, walaupun kelas kesesuaian lahan untuk beberapa komoditas didominasi oleh kelas S3 (sesuai marginal) dan $\mathrm{N}$ (tidak sesuai). Kelas S3 (sesuai marginal), menunjukkan bahwa lahan mempunyai faktor pembatas yang berat sehingga mempengaruhi produktivitas komoditas tersebut. Kelas kesesuian lahan S3 memerlukan tambahan masukan untuk mengatasi faktor pembatas. Sedangkan kelas kesesuaian lahan $\mathrm{N}$ (tidak sesuai) mempunyai faktor pembatas yang sangat berat atau sulit untuk diatasi. Faktor pembatas yang paling berpengaruh adalah berupa drainase dan tekstur tanah pada wilayah pesisir didominasi tekstur pasir dengan drainase sangat cepat. Pada Tabel 8 menunjukkan bahwa tidak semua komoditas yang termasuk komoditas unggulan memiliki kelas kesesuaian lahan yang sesuai.
Sebagian besar komoditas memiliki kesesuaian lahan S3 dan N, walaupun pada kenyaataan di lapangan komoditas tersebut masih dapat tumbuh dan menghasilkan produksi yang tinggi. Hal tersebut dilakukan dengan mengatasi faktor pembatas yaitu melalui manajeman air untuk mengatasi drainase dan rekayasa mikroklimat untuk mengatasi faktor tekstur tanah. Rekayasa lahan mikroklimat dilakukan dengan pupuk organik, mulsa dan juga sistem irigasi. Hal tersebut menunjukkan bahwa pengembangan masih dimungkinkan apabila dilakukan tindakan pengelolaan lahan yang lebih intensif untuk mengatasi faktor pembatasnya.

Sedangkan pada bidang peternakan, kesesuaian lahan lingkungan untuk pengembangan peternakan ruminansia kecil yang berdasarkan hasil analisis komoditas unggulan adalah domba, termasuk dalam kelas kesesuaian lahan yang sesuai. Hal tersebut menunjukkan bahwa peternakan ruminansia kecil sangat berpotensi untuk diternakkan dan menjadi komoditas unggulan di wilayah pesisir Purworejo. 
Pada bidang perikanan, budidaya tambak udang dan ikan nila/mujahir memiliki kelas kesesuaian lahan S3 (Sesuai Marginal) dan N (tidak sesuai). Faktor pembatas yang paling berpengaruh adalah tekstur tanah yang berupa pasir sehingga tidak mampu menahan air. Pada tipologi pesisir pengendapan laut dengan karakteristik lahan berupa relief datar-landai, materi penyusun utama pasir, dan proses genesa adalah marin, seperti pada wilayah pesisir Purworejo, dapat dimanfaatkan untuk usaha perikanan melalui rekayasa teknik khusus untuk mengatasi kendala materi pasir yang tidak mampu menahan air (Khakim, 2009). Teknologi biocrete merupakan rekayasa teknologi yang dapat memecahkan permesalahan tersebut, termasuk yang dilakukan petani tambak di pesisir Purworejo. Teknologi ini berbeda dengan budidaya tambak pada umumnya. Dinding kolam menggunakan campuran plastik, anyaman bambu, ijuk dan semen, sedangkan untuk dasar kolam menggunakan media plastik. Pada wilayah pesisir Purworejo, sebagian besar petani tambak menggunakan media terpal plastik yang bertujuan untuk menghindari kerugian akibat terkumpulnya lapisan lumpur pada permukaan dasar kolam yang menciptakan media pembiakan virus dan gangguan lain yang merusak budidaya udang. Metode pembuangan limbah memiliki lubang pembuangan yang berada di atas permukaan tanah, sehingga mempermudah pemanenan. Sehingga meskipun secara kelas kesesuaian lahan, perikanan tambak di pesisir Purworejo tidak sesuai, namun hal tersebut masih dapat dikembangkan dengan rekayasa teknik biocrete.

\section{Penutup}

Komoditas unggulan wilayah pesisir selatan Purworejo pada sektor pertanian berupa padi ladang, padi sawah, jagung, ketela rambat, kelapa deres, tebu, jambu mete, kambing, domba, ayam, itik, entog, kelinci, serta perikanan tambak. Berdasarkan kelas kesesuaian lahan, tidak semua komoditas unggulan pertanian memiliki kelas kesesuaian lahan yang sesuai, akan tetapi dengan teknologi pertanian dan perikanan untuk mengatasi faktor pembatasnya, komoditas-komoditas tersebut masih memiliki potensi yang besar untuk menjadi komoditas unggulan apabila dilihat dari aspek pasar, harga dan juga produksi.

Disarankan pada penelitian selanjutnya untuk dapat menvalidasi data yang diperoleh dengan observasi lapangan. Mengingat pada saat penilitian ini dilakukan sedang terjadi pandemi sehingga membatasi penelitian dalam memperoleh data yang valid dan sebagian besar data yang didapatkan bersifat data sekunder. Mengingat bahwa wilayah penelitian merupakan wilayah yang rawan terhadap tsunami, disarankan pada penelitian-penelitian yang akan datang dan berkaitan dengan wilayah pesisir daerah penelitian perlu dilakukan penelitian tentang tsunami. Penelitan tersebut dapat mencakup pada model tsunami yang mungkin terjadi dan cakupan wilayah pesisir yang terkena dampaknya agar dapat diprediksi tentang kemungkinan pengembangan dan pengelolaan wilayah pesisir secara lebih menyeluruh. 


\section{Ucapan Terima Kasih}

Penulis mengucapakan terima kasih kepada bapak Dr. Sudrajat, M.P dan Dr. Andri Kurniawan, M.Si selaku dosen pembimbing yang telah melibatkan peneliti dalam Penelitian Hibah RTA 2020 dari Direktorat Penelitian UGM untuk menyusun Tugas Akhir.

\section{Daftar Pustaka}

Ahaliki, B. (2016). Sistem Informasi Geografis (Sig) Pemetaan dan Analisis Daerah Pertanian Di Kabupaten Gorontalo. Jtech 2016, 4(2) 116 - 122. Program Studi Teknik Informatika, Politeknik Gorontalo

Alecsandru, S. V. \& Raluca, D.A. (2015). A Regional Level Hierarchy of the Main Foreign Direct Investments' DeterminantsEmpirical Study, The Case of Romanian Manufacturing Sector. Procedia Social and Behavioral Science. Eng., 181, 321-330.

Djaenudin, D., Marwan H., Subagjo, H. A., Hidayat. (2011). Petunjuk Teknis Evaluasi Lahan Untuk Komoditas Pertanian. Balai Besar Penelitian dan Pengembangan Sumberdaya Lahan Pertanian. Balitbang Pertanian. Bogor

Djunaedi, A. \& Basuki, N. (2002.). Perencanaan pengembangan kawasan pesisir. Jurnal Teknologi Lingkungan, 3(3), 225-231.

Harinta, Y. W., Basuki, J. S., \& Sukaryani, S. (2018). Pemetaan dan Pengembangan Agribisnis Komoditas Unggulan Sayuran di Kabupaten Karanganyar. Agriekonomika, 7(1), 37-47. https://doi.org/10.21107/agriekon omika.v7i1.3201

Kawik, S. (2003). Pengenalan Perencanaan Wilayah Pantai. Yogyakarta: UGM Press.

Khakim, N. (2009). Kajian Tipologi Fisik Pesisir Daerah Istimewa Yogyakarta untuk Mendukung Pengembangan dan Pengelolaan Wilayah Pesisir. Disertasi. Program Studi Pengelolaan Sumberdaya Pesisir dan Lautan. Institut Pertanian Bogor.

Mustofa, A. (2012). Kriteria Kesesuaian Lahan Untuk Berbagai Komoditas Tambak. Media Akuakultur, 7(2).

Permana, C. D. \& Asmara, A. (2010). Analisis Peranan dan Dampak Investasi Infrastruktur Terhadap Perekonomian Indonesia: Analisis Input-Output. J. Manajemen dan Agribisnis, 7 (7), 48-58.

Poerwadi, B. S. (2018). Refleksi 2017 dan Outlook 2018 Membangun dan Menjaga Ekosistem Laut Indonesia Bersama Ditjen Pengelolaan Ruang Laut (Siaran Pers). Kementerian Kelautan dan Perikanan.

Resosudarmo, B. P., Nina I. L. S., \& Budi, R. (2000). The Indonesian Marine Resources: An Overview of Their Problems And Challenges. The Indonesian Quarterly. VOL. XXVIII, NO. 3. Third Quarter. Center for Strategic and International Studies. Jakarta. 2000

Rismana, N., Atmiyanti, \& Ridwan (2006). Pembuatan Peta Kesesuaian Ekologis Untuk Ternak Ruminansia Pada Skala Tinjau. Temu Teknis Nasional 
Tenaga Fungsional Pertanian. Balai Penelitian Ternak. Bogor

Sari, R. M. (2010). Analisis Komoditas Unggulan Pertanian di Pulau Buru Provinsi Maluku. Jurnal Agroforestry, 5(3), 228-236.

Setiawan, B. (2004). Tata Ruang dan Lingkungan Hidup. Yogyakarta. UGM

Sumanto. E., \& Juarini. (2006). Potensi Kesesuaian Lahan untuk Pengembangan Ternak Ruminansia di Provinsi Nusa Tenggara Timur. Prosiding Seminar Nasional Teknologi Peternakan dan Veteriner, Iptek Sebagai Motor Penggerak Pembangunan Sistem dan Usaha Agribisnis Peternakan. Puslitbangnak, Balitbangtan. Bogor

Suprapto, O., Syawaludin, A. H., \& Herawati, T. (2016). Analisis Kerentanan Fisik Pantai Di Pesisir Garut Selatan Jawa Barat. Jurnal Perikanan Kelautan, (7)2, 51-57

Suratman, W., Suharyadi, \& Suharyanto. (1993). Evaluasi Kemampuan Lahan untuk Perencanaan Penggunaan Lahan dengan Metode GIS di Propinsi Daerah Istimewa Yogyakarta. Yogyakarta: UGM Press.

Wahyunto, Hikmatullah, E., Suryani, C., Tafakresnanto, S., Ritung, A., Mulyani, Sukarman, K., Nugroho, Y., Sulaeman, Y., Apriyana, Suciantini, A., Pramudia, Suparto, R. E., Subandiono, T., Sutriadi, D., \& Nursyamsi. (2016). Petunjuk Teknis Pedoman Penilaian Kesesuaian Lahan untuk Komoditas Pertanian Strategis Tingkat Semi Detail Skala 1:50.000.
Balai Besar Penelitian dan Pengembangan Sumberdaya Lahan Pertanian, Badan Penelitian dan Pengembangan Pertanian Bogor. 